\title{
Impact of Air Pollution on Semen Quality: The Specific Situation of Terni (Central Italy)
}

\author{
Ilaria Bocci ${ }^{1 \#}$, Giulia Poli ${ }^{2 \# *}$, Consuelo Fabi ${ }^{3}$, Francesco Bronzini ${ }^{4}$, Giulia Ceccotti ${ }^{5}$ and Stefano \\ Brancorsini $^{2}$ \\ ${ }^{1}$ Department of Laboratory Medicine, Policlinico Tor Vergata of Rome, Italy
}

${ }^{2}$ Department of Medicine and Surgery, University of Perugia, Terni, Italy

${ }^{3}$ Andrology and Urogynecology Clinic, Santa Maria Terni Hospital, University of Perugia, Terni, Italy

${ }^{4}$ Santa Maria Terni Hospital, University of Perugia, Italy

${ }^{5}$ Santa Maria Terni Hospital, University of Perugia, Italy

"These authors contributed equally to this work

*Corresponding author: Giulia Poli, University of Perugia, Department of Medicine and Surgery, Via Mazzieri 3, 05100 Terni, Italy

\section{ARTICLE INFO}

Received:

Published: 慧 September 17, 2021

Citation: Ilaria Bocci, Giulia Poli, Consuelo Fabi, Francesco Bronzini, Giulia Ceccotti, Stefano Brancorsini. Preparation of 3D-Porous Graphene Aerogel for High-Performance Anode of Lithium-Ion Batteries. Biomed J Sci \& Tech Res 38(5)2021. BJSTR. MS.ID.006207.

Keywords: Male Infertility; Air pollution; Seminal Fluid; Environment

\section{ABSTRACT}

To evaluate the impact of environmental pollution on male fertility, seminal biofluid parameters of man living in the contaminated urban area of Terni-Papigno, were comparated with those who live in rural areas with low risk of pollution. Patients referred to the Seminology Laboratory of the Division of Andrology and Urology Department were enrolled for infertility evaluation. Semen samples were evaluated for seminal volume, $\mathrm{pH}$, total sperm count, progressive motility, and morphology and leukocyte concentration. Data were analyzed with GraphPad Prism 6.0 and results were reported as mean \pm standard deviation (SD). We report an association between ambient air pollution and sperm quality. In patient residents in areas with high environment exposure, sperm quality especially sperm concentration and count decrease significantly. Sperm motility, morphology and vitality did not demonstrated statistical differences. Identifying risk factors to improve the management of human wellness and health throughout standardized analysis, which correlates the toxic bioaccumulation of the seminal fluid with semen parameters, might be the main objective to be considered in public prevention policies.

Abbreviations: SD: Standard Deviation; WHO: The World Health Organization; CO: Carbon Monoxide; $\mathrm{NO}_{2}$ : Nitrous Dioxide; $\mathrm{SO}_{2}$ : Sulfur Dioxide; ROS: Reactive Oxidative Species; $\mathrm{PM}_{10}$ : Particulate Matter With Diameter Less Than 10 Microns; ARPA: Regional Agency for Environmental Protection

\section{Introduction}

Infertility is a prevalent condition affecting an estimated 72, 4 million people globally that is well recognized by The World Health Organization (WHO). Although prevalence data are lacking, 9\% of couples struggle with fertility issues and male factor contributes to $50 \%$ of the issues. Many genetic and lifestyle factors have been implicated in male infertility; however, about $30 \%$ of cases are still thought to be idiopathic [1]. The mechanism by which medical conditions affect fertility includes effects on hormonal levels, impairment of sexual function (including ejaculatory function), or impairment of testicular function/spermatogenesis. In the last 70 years, a decrease in sperm fertility and quality has been observed, including sperm count, ejaculate volume, alterations in sperm concentration and morphology [2]. Recent studies suggest that men with abnormal semen parameters have a higher risk of 
testicular malignancy [3]. Nowadays, environmental and lifestyle factors could be possible contributors to infertility conditions, such as use of smoke sigarettes, increasing of both parents age conception, abuse of alcohol and drugs, physical inactivity, obesity, social stress, exposure to environmental contaminants (polycyclic aromatic hydrocarbons-PAHs, or heavy metals, for examples) and air pollution $[4,5]$. In particular, epidemiological and experimental studies explained the link between air pollution and alterations of sperm parameters as the main risk factors for male infertility.

Human activities such as transport, industrial and agricultural emission are considered the main causes of air pollution (solid particles, liquid droplets or gases), and people that living near these area, are more exposed to henanced emission source of carbon monoxide (CO), nitrous dioxide $\left(\mathrm{NO}_{2}\right)$, sulfur dioxide $\left(\mathrm{SO}_{2}\right)$, ozone and lead [6]. Ambient air pollution is associated with systemic increases in oxidative stress, to which sperm are particularly sensitive. In this contest, reactive oxidative species (ROS) have been related with a broad array of spermatogenensis effects, including the decrease of progressive motile sperm count, viability, abnormal sperm morphology, and fertilization rate and spermatogenic cell numbers [7]. In Italy, 12,482 areas with a high risk of environmental pollution, mainly due to industrial emission, were been identified. Some central provinces, such as Città di Castello, Foligno and Perugia exceeded the limit set for particulate matter with diameter less than 10 microns $\left(\mathrm{PM}_{10}\right)$ and $\mathrm{O}_{3}$ emissions, in 2019. In particular, Terni is one of the most polluted urban and industrial area in Central Italy [8]. In fact, is situated in an intermountain depression, delimited by the Apennine mountain range. This area is characterized by the presence of typical urban $\mathrm{PM}_{10}$ emission sources such as vehicular traffic, domestic heating and industrial emission sources from a power plant for waste treatment. Peculiar geomorphological and meteorological conditions of Terni basin, limit the dispersion and augment the accumulation of the atmospheric pollutants.

The "Thyssen Krupp AST", a large steel factory founded at the

Table 1: Demographic and environmental patient's classification. end of $19^{\text {th }}$ century and two more recent chemical industrial areas, are located close to the city center [9]. As a result of the intensive industrial activities and the geographical location, atmospheric pollution is the major local issue with high PM concentrations occurring throughout the year. According to European Commission Law, the daily maximum $\mathrm{PM}_{10}$ concentration allowed in cities is 50 $\mu \mathrm{g}-3$ [9]. The threshold has not to exceede more than 35 times per year. In Terni, the atmospheric $\mathrm{PM}_{10}$ concentration exceede that daily limit on more than 70 days in 2012, as recorded by Regional Agency for Environmental Protection (ARPA), Umbria. The aim of the present study is to provide an association between ambient air pollution and sperm quality, analyzing seminal biofluid parameters of man living in the urban area of Terni- Papigno, with a high risk of pollution, comparated with those who live in rural areas with low risk of pollution.

\section{Materials and Methods}

\section{Study Participants}

Signed written consent was obtained from all 52 participants (age of 20-40 years) enrolled in this study from January 2018 to December 2019. Patients referred to the Seminology Laboratory of the Division of Andrology and Urology Department for an infertility evaluation. Female partners of the infertile men were subjected to general gynecological evaluation and were reported to have normal reproductive health. Residence in the province of Terni was an inclusion criteria while, systemic and cronic disease, genetic abnormalities, alcohol or drug abuse, hormone treatment, varicocele infection microchidism and cryptorchidism, prostatitis and other factors that could affect semen quality (such as fever, medications, exposure to $\mathrm{X}$ rays etc.) were exclusion criteria. Men were divided in group A and B that includes 30 patients from the high pollution environmental risk area of Terni-Papigno and 22 subjects that live in neighboring areas, with a low risk of pollution, respectively (Table 1 ).

\begin{tabular}{|c|c|c|c|c|}
\hline Groups & Enviromental risk & Population Density & PM $_{\mathbf{1 0}}$ & NO $_{\mathbf{2}}$ \\
\hline A (n=30) & SNI & Urbanized Area & Class 3 (12\% of the surface) & $\begin{array}{c}\text { Class 4 (11,8\%) } \\
\text { Class 3 (2,8\%) }\end{array}$ \\
\hline B (n=22) & - & Rural Area & Prevalence of Class 1 and 2 & Prevalence of Class 1 and 2 \\
\hline
\end{tabular}

Note: SNI: Sites of National Interest; $\mathrm{PM}_{10}$, Particulate Matter $\leq 10 \mu \mathrm{m} ; \mathrm{NO}_{2}$, Nitrogen dioxide; OCSE Organization for Economic Cooperation and Development, class 1 and 2: rural area with population density $<150$ inhabitants $/ \mathrm{km}^{2}$ and $\mathrm{PM}_{10}<10 \mu \mathrm{g} / \mathrm{m} 3 ; \mathrm{class}$ 3 and 4: rural area with population density $>150$ inhabitants $/ \mathrm{km}^{2}$ and $\mathrm{PM}_{10}>10 \mu \mathrm{g} / \mathrm{m} 3$

\section{Semen Analysis and Preparation of Samples}

Semen samples were collected at the Andrology and Urology Laboratory by masturbation into a sterile container after 2-7 days of sexual abstinence and were analyzed immediately after liquefaction, according to the WHO guidelines [10]. Each sample was evaluated for seminal volume, $\mathrm{pH}$, total sperm count, progressive motility, and morphology and leukocyte concentration. Semen volume was measured by graduated pipettes. Calibration strips were used to measure the seminal fluid $\mathrm{pH}$. For the evaluation of the sperm concentration, following semen liquefaction, $10 \mu \mathrm{L}$ of non-diluted, 
well-mixed semen sample was at first loaded in the middle of a clean Burker counting chamber, maintained at the temperature of $37^{\circ} \mathrm{C}$, gently covered with a cover glass, and examined using $200 \times$ or $400 \times$ magnification. The sample was diluted before proceeding with the sperm count. 1:2 dilution was used, strictly following the WHO 2010 manual recommendations [10]. The final concentration was calculated as: [(number of spermatozoa counted/the number of lines) $\mathrm{x}$ dilution factor] and expressed as 106 spermatozoa/mL. To evaluate the sperm motility, immediately after semen liquefaction, $10 \mu \mathrm{L}$ of undiluted, well-mixed semen sample was loaded in the middle of a clean Neubauer counting chamber, maintained at the temperature of $37{ }^{\circ} \mathrm{C}$, gently covered with a cover glass, and examined using $200 \times$ magnification.

Sperm motility was assessed in 200 random spermatozoa and characterized as progressive and non-progressive motility. The total motility was calculated as the sum of progressive and non-progressive motility. Both progressive and total motility were expressed as percentages. Sperm morphology was evaluated in 200 spermatozoa and the value was expressed as percentages. Finally, the vitality was assessed using eosin staining according to the WHO recommendations [10].

\section{Statistical Analysis}

Data were analyzed with GraphPad Prism 6.0. Results were reported as mean \pm standard deviation (SD) Analysis of variance and Kruskal-Wallis tests were performed. The significance threshold was set at 0.05 .

\section{Results}

Patients were classified according to Demographic and Environmental characteristics (Table 1) Total sperm count (Figure 1) and sperm concentration (Figure 2) decreased significantly in seminal biofluid of patients living in urbanized area of TerniPapigno (group A) when compared to subjects who lived in rural areas (group B). Seminal volume $(\mathrm{mL})$ did not reach significant difference (Figure 3) between the groups considered.

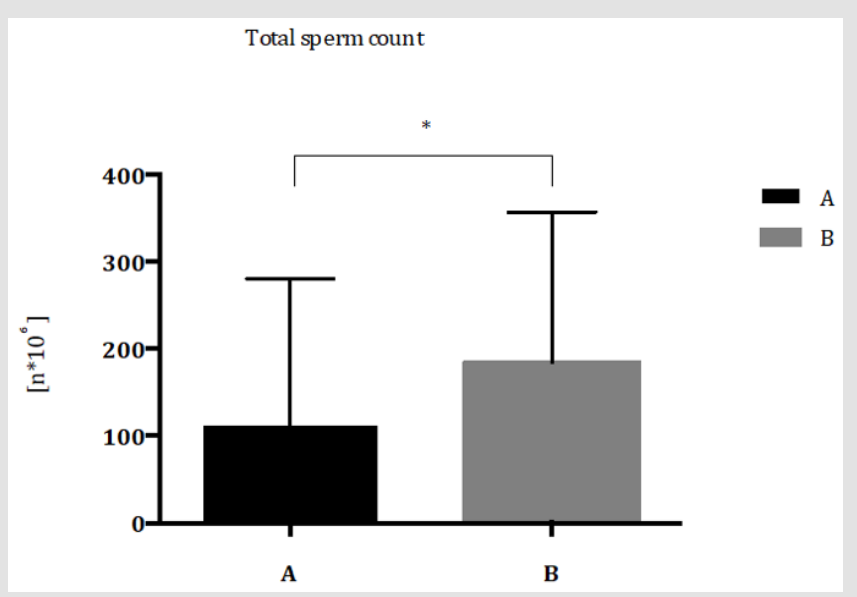

Figure 1: Total sperm count ( $\left.n^{*} 106\right)$ expressed as median with range and interquartile range in group A compared to group B. ${ }^{*} \mathrm{P}<0,05$.

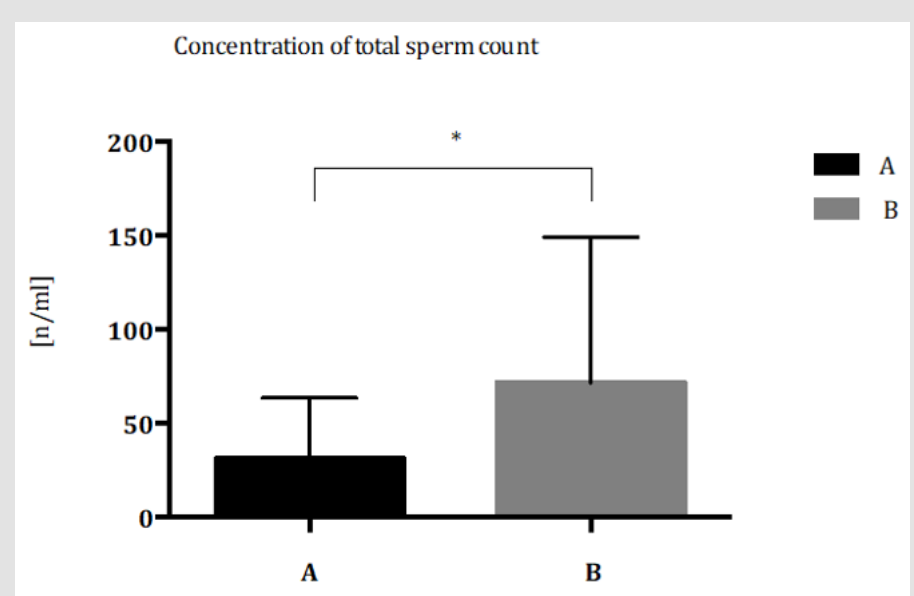

Figure 2: Concentration of total sperm concentration $(\mathrm{n} / \mathrm{ml})$ expressed as median with range and interquartile range in group A compared to group B. *P<0,05. 


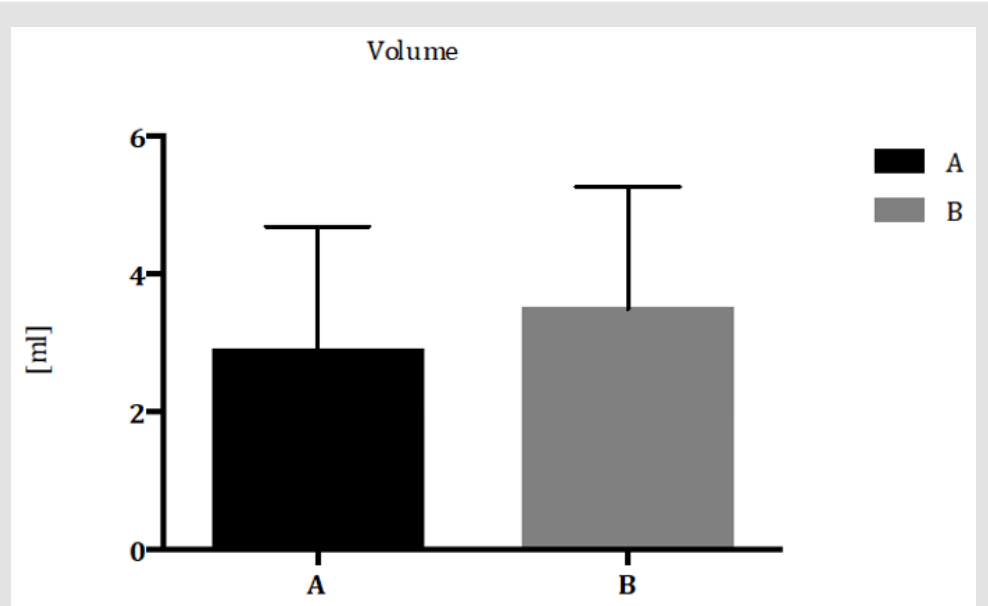

Figure 3: Seminal volume $(\mathrm{ml})$ expressed as median with range and interquartile range in group A compared to group B. ${ }^{*} \mathrm{P}<0,05$.

\section{Discussion}

In this study, conventional semen parameters (volume, appearance, $\mathrm{pH}$, motility, and viability, and morphology, presence of aggregations, agglutination and leukocyte concentration) were analyzed for each sample according to the 2010 WHO criteria. Our results showed a significant decrease of total sperm count in group A patients respect to group B subjects (Figure 1). Nowadays, several studies showed how pollution can affect human fertility. Sperm count and sperm motility were reduced in men living in polluted cities. A decrease of sperm count was observed in America and Northern Europe during the last 50 years [2] and the reduction of semen quality and sperm count especially in industrialized countries supports the evidence that adverse environmental factors are key factors for men infertility [11]. Furthermore, different studies reported the enhancement of infertility, urogenital malformation and chronic disease (cancer, diabetes, etc.) in areas with a high environmental pressure [12]. In group A, a significant decrease of sperm concentration was demonstrated, respect to group B patients (Figure 2). In 2019, a longitudinal analysis on 8.945 semen samples, suggested the specific role of $\mathrm{O}_{3}$ pollution in sperm concentration [13]. The effect of air pollutants and ozone on sperm quality, was strongly elucidated by Sokol, et al. [14]; they reported that pollutants have no effect on sperm quality, however, ozone could make changes in sperms, including sperm DNA fragmentation via oxidative stress, resulting in decreased fertility [14].

The toxicity of $\mathrm{O}_{3}$ was largely demonstrated to be the major oxidant of photochemical smog and its exposure produces reactive ROS at respiratory level $[15,16]$. Extra pulmonary toxicity suggests that $\mathrm{O}_{3}$ or $\mathrm{O}_{3}$ reaction-products can cross blood-gas barrier and be absorbed into the circulating bloodstream, creating an environment caring to an inflammatory reaction $[17,18]$. It is unclear how
$\mathrm{O}_{3}$ can negatively affect sperm quality, but $\mathrm{O}_{3}$-induced oxidative stress could be a possible mechanism, through which testicular and sperm function could be altered $[19,20]$. Under physiologic conditions, spermatozoa exist in a balanced environment of ROS and antioxidants, where ROS determine the biochemical steps required for normal fertilization (capacitation and the acrosome reaction). However, excessive amounts of ROS produced by leukocytes and immature spermatozoa can damage mature spermatozoa and the integrity of sperm DNA [21,22]. Concerning seminal volume (mL), our results did not reach significant difference between groups considered (Figure 3). Several studies suggested that alterations of semen parameters, including volume, progressive motility, total motility or morphology, may not relate to air pollution [23]. Several works observed a reduction of both sperm motility and morphology, associated with air heavy metals (lead, mercury and cadmium) [24,25], that determine alterations in sperm DNA.

Rubes and colleagues showed that short-term exposure to pollutants caused serious damages in men and women's reproductive system. Moreover, this study demonstrated that the incidence of sperm DNA alterations due to air pollution is higher in middle-aged men [26]. Also, exposition time of contaminants seem to be determinant, in fact a study of Hammoud showed that 3 months exposure to air pollution decreases motility levels, while removing contamination can restore normal parameters levels [27]. In an extensive cross-sectional study, Xu and co-workers, founded a strong correlation between motility, concentration, and morphology of semen biofluid of men exposed to air pollutants with the use of cigarette and alcohol [28]. On the other hand, Selevan, et al. [29] did not observed any relevant alerations in sperm count, motility and morphology of young men exposed to air pollutants, except for sperm DNA and chromatin [29]. Moreover, several authors specify that the morphological change of spermatozoa after exposure to pollutants is not an indicative diagnostic parameter. Association 
between air pollution and alteration of specific semen parameters is not clear and different relevant factors, such as geographic areas and lifestyle, should be considered for male infertility diagnosis.

\section{Conclusion}

The current study provides evidence of an association between ambient air pollution and sperm quality. Patient residents in areas with high environment exposure had a significantly decrease in sperm quality especially for sperm concentration and count but had no impact on the other sperm parameters of spermogram (motility, morphology, vitality). The individual role of specific pollutants is difficult to identify, since patient in this study are typically exposed to several pollutants simultaneously. The physiopathology leading to altered fertility is poorly understood. In the literature there are forward four mechanisms to explain the negative impact of air pollution on sperm, as hormonal disturbances, oxidative stress induction (ROS), cell DNA and epigenetic alterations, probably working in combination. Clearly, more research is needed to understand the detrimental effect of the pollutants on sperm and to characterize their action in more detail. Our results suggest the important role of human sperm as an early and sensitive biomarker of environmental pollution as it could represent an ideal tool for investigating and promoting health surveillance especially in environmental risk areas. Environmental contaminants and bad lifestyles can impair reproductive health and overall health, encouraging the development of chronic degenerative diseases affecting the adult and, through the sperm epigenome changes, future generations. Thus, identifying risk factors to improve the management of human wellness and health throughout standardized analysis, which correlates the toxic bioaccumulation of the seminal fluid with the multiple semen parameters, might be the main objective to be considered in public prevention policies.

\section{Acknowledgement}

This work was supported by Fondazione Cassa di Risparmio Terni e Narni.

\section{Conflicts of Interest}

The authors declare that there is no conflict of interest regarding the publication of this paper.

\section{References}

1. Boivin J, Bunting L, Collins JA, Nygren KG (2007) International estimates of infertility prevalence and treatment-seeking: Potential need and demand for infertility medical care. Hum Reprod 22(6): 1506-1512.

2. Carlsen E, Giwercman A, Keiding N, Skakkebaek NE (1992) Evidence for decreasing quality of semen during past 50 years. BMJ 305(6854): 609613.

3. Raman JD, Nobert CF, Goldstein M (2005) Increased incidence of testicular cancer in men presenting with infertility and abnormal semen analysis. J Urol 174(5): 1819-1822.
4. Gollenberg AL, Liu F, Brazil C, Drobnis EZ, Guzick D, et al. (2010) Semen quality in fertile men in relation to psychosocial stress. Fertil Steril 93(4): 1104-1111.

5. Deng Z, Chen F, Zhang M, Lan L, Qiao Z, et al. (2016) Association between air pollution and sperm quality: A systematic review and meta-analysis. Environ Pollut 2208: 663-669.

6. Unger N, Bond TC, Wang JS, Koch DM, Menon S, et al. (2010) Attribution of climate forcing to economic sectors. Proc Natl Acad Sci USA 107(8): 3382-3387.

7. Al Akhras MA, Elbetieha A, Hasan MK, Al Omari I, Darmani H, et al. (2001) Effects of extremely low frequency magnetic field on fertility of adult male and female rats. Bio electromagnetics 22(5): 340-344.

8. Moroni B, Ferrero L, Crocchianti S, Perrone MG, Sangiorgi G, et al. (2013) Aerosol dynamics upon Terni basin (Central Italy): Results of integrated vertical profile measurements and electron microscopy analyses. Rend Fis Acc Lincei 24(4): 319-328.

9. Sgrigna G, Sæb $\varnothing$ A, Gawronski S, Popek R, Calfapietra C (2015) Particulate Matter deposition on Quercus ilex leaves in an industrial city of central Italy. Environ Pollut 197: 187-194.

10. Cooper TG, Noonan E, Von Eckardstein S, Auger J, Baker HW, et al. (2010) World Health Organization reference values for human semen characteristics. Hum Reprod Update 16(3): 231-245.

11. Zhou N, Cui Z, Yang S, Han X, Chen G, et al. (2014) Air pollution and decreased semen quality: A comparative study of Chongqing urban and rural areas. Environ Pollut 187: 145-152.

12. Pasetto R, Zengarini N, Caranci N, De Santis M, Minichilli F, et al. (2017) Environmental justice nel sistema di sorveglianza epidemiologica SENTIER. Epidemiol Prev 41(2): 134-139.

13. Zhang HT, Zhang Z, Cao J, Tang WH, Zhang HL, et al. (2019) Ambient ozone pollution is associated with decreased semen quality: Longitudinal analysis of 8945 semen samples from 2015 to 2018 and during pollution- control period in Beijing, China. Asian J Androl 21(5): 501-507.

14. Sokol RZ, Kraft P, Fowler IM, Mamet R, Kim E, et al. (2016) Exposure to environmental ozone alters semen quality. Environ Health Perspect 114(3): 360-365.

15. Gurgueira SA, Lawrence J, Coull B, Murthy GG, González Flecha B (2002) Rapid increases in the steady-state concentration of reactive oxygen species in the lungs and heart after particulate air pollution inhalation. Environ Health Perspect 110(8): 749-755.

16. Menzel DB (1984) Ozone: An overview of its toxicity in man and animals. J Toxicol Environ Health. 13(2-3): 183-204.

17. Boorman GA, Hailey R, Grumbein S, Chou BJ, Herbert RA, et al. (1994) Toxicology and carcinogenesis studies of ozone and ozone 4-(N-nitrosomethylamino)-1-(3-pyridyl)-1-butanone in Fischer-344/N rats. Toxicol Pathol 22(5): 545-554.

18. Mustafa MG (1990) Biochemical basis of ozone toxicity. Free Radic Biol Med 9(3): 245-265.

19. Agarwal A, Saleh RA, Bedaiwy MA (2003) Role of reactive oxygen species in the pathophysiology of human reproduction. Fertil Steril 79(4): 829843.

20. Diemer T, Allen JA, Hales KH, Hales DB (2003) Reactive oxygen disrupts mitochondria in MA-10 tumor Leydig cells and inhibits steroidogenic acute regulatory (StAR) protein and steroidogenesis. Endocrinology 144(7): 2882-2891.

21. Aitken J, Fisher H (1994) Reactive oxygen species generation and human spermatozoa: The balance of benefit and risk. Bioessays 16(4): 259-267.

22. Sikka SC, Rajasekaran M, Hellstrom WJ (1995) Role of oxidative stress and antioxidants in male infertility. J Androl 16(6): 464-468. 
23. Huang Q Liu L, Wu Y, Wang X, Luo L, et al. (2019) Seminal plasma metabolites mediate the associations of multiple environmental pollutants with semen quality in Chinese men. Environ Int 132: 105066

24. Akinloye 0, Arowojolu AO, Shittu OB, Anetor JI (2006) Cadmium toxicity: A possible cause of male infertility in Nigeria. Reprod Biol 6(1): 17-30.

25. Guillette LJ Jr, Edwards TM (2008) Environmental influences on fertility: Can we learn lessons from studies of wildlife? Fertil Steril 89(2): e21-24.

26. Rubes J, Evenson D (2007) Impact of air pollution on reproductive health in Northern Bohemia. Reprod Health Environ, pp. 207-224.

\section{ISSN: 2574-1241}

DOI: 10.26717/BJSTR.2021.38.006207

Giulia Poli. Biomed J Sci \& Tech Res

This work is licensed under Creative Commons Attribution 4.0 License

Submission Link: https://biomedres.us/submit-manuscript.php
27. Hammoud A, Carrell DT, Gibson M, Sanderson M, Parker Jones K, et al. (2010) Decreased sperm motility is associated with air pollution in Salt Lake City. Fertility and Sterility 93(6): 1875-1879.

28. Xu W, Bao H, Liu F, Liu L, Zhu YG, et al. (2012) Environmental exposure to arsenic may reduce human semen quality: associations derived from a Chinese cross-sectional study. Environ Health 11: 46.

29. Selevan SG, Borkovec L, Slott VL, Zudová Z, Rubes J, et al. (2000) Semen quality and reproductive health of young Czech men exposed to seasonal air pollution. Environ Health Perspect 108(9): 887-894.

$\begin{array}{ll}\text { BIOMEDICAL } & \text { Assets of Publishing with us } \\ \text { RESEARCHES } & \text { - Global archiving of articles } \\ \text { - Immediate, unrestricted online access }\end{array}$

